\section{A.A. El Solh}

Division of Pulmonary, Critical Care and Sleep Medicine, Dept of Medicine, University at Buffalo School of Medicine and Biomedical Sciences, Buffalo, NY, USA.

\section{REFERENCES}

1 El Solh AA, Saliba R, Bosinski T, Grant BJ, Berbary E, Miller N. Allopurinol improves endothelial function in sleep apnea: a randomised controlled study. Eur Respir J 2006; 27: 997-1002.
2 Moens AL, Goovaerts I, Claeys MJ, Vrints CJ. Flowmediated vasodilation: a diagnostic instrument, or an experimental tool? Chest 2005; 127: 2254-2263.

3 Sorensen KE, Dorup I, Hermann AP, Mosekilde L. Combined hormone replacement therapy does not protect women against the age-related decline in endothelium-dependent vasomotor function. Circulation 1998; 97: 1234-1238.

\title{
ACE inhibitors prevent aspiration pneumonia in Asian, but not Caucasian, elderly patients with stroke
}

\section{To the Editors:}

In a recent issue of the European Respiratory Journal, VAN DE GARDE et al. [1] demonstrated that the use of angiotensinconverting enzyme (ACE) inhibitors is not associated with a decreased risk of hospitalisation for community-acquired pneumonia (CAP) in a general, essentially white population. Their conclusion that the beneficial effect of ACE inhibitors on pneumonia risk is not observed in a general white population is in contrast with previous findings in Asian populations [1]. This was an excellent good study examining the association of ACE inhibitor treatment of cardiovascular disease with a risk reduction of CAP using a large sample size. The results are acceptable and not surprising; however, the discussion and conclusion are misleading.

As shown in table 1, there are controversies regarding the ACE inhibitor effects on the risk reduction of pneumonia even in Asian countries; furthermore, the study samples are very different among the studies. In a prospective study by SEKIZAWA et al. [2], ACE inhibitor use reduced pneumonia incidence for 2 yrs. They did not examine the general population; subjects were hypertensive elderly patients with a history of stroke or lacuna infarction, and a mean age $10 \mathrm{yrs}$ older than that of the study by VAN DE GARDE et al. [1]. However, the study by ARAI et al. [3] examined the association of ACE inhibitors and the risk reduction of pneumonia in the general hypertensive elderly without stroke in Japan [3]. Surprisingly, they had an $8.3-8.9 \%$ incidence of pneumonia over $3 \mathrm{yrs}$, an incidence twenty times higher than the previous data $[6,7]$. It is hard to believe that $\sim 3 \%$ of hypertensive elderly outpatients without major complications suffered from pneumonia. We have previously presented data showing no association of ACE inhibitor use with pneumonia risk in elderly hypertensive subjects without stroke history [4]. Since ACE inhibitors, through the inactivation substance $P$, improve upper airway reflexes such as swallowing and cough, resulting in the reduction of aspiration pneumonia in elderly patients, they may not reduce the CAP in those patients without deglutition problems. Current evidence indicates that ACE inhibitors play a significant role in the prevention of aspiration pneumonia in the elderly, but not in common CAP in healthy adults. This was confirmed by the sub-analysis of the Perindopril Protection Against Recurrent Stroke Study (PROGRESS). OHKUBO et al. [5] re-analysed the PROGRESS data concerning the incidence of pneumonia. ACE inhibitoractive treatment significantly reduced the risk of pneumonia among participants of Asian ethnicity (mean (95\% confidence interval) $47 \%(14-67 \%), p=0.01)$, with no significant effect among non-Asian participants $(5 \%(-27-29 \%), p=0.7 ; p$ for homogeneity $=0.04)$. These findings add to the body of

TABLE 1 The association of angiotensin-converting enzyme (ACE) inhibitor use and the rate of pneumonia in different trials

\begin{tabular}{|c|c|c|c|c|c|c|}
\hline & VAN DE GARDE [1] & Sekizawa [2] & Aral [3] & TERAMOTO [4] & Онкиво [5] & Онкиво [5] \\
\hline Race & Caucasian & Asian & Asian & Asian & Asian & Caucasian \\
\hline Subjects $n$ & 4925 & 440 & 576 & 358 & 2352 & 3753 \\
\hline Observation period yrs & 6 & 2 & 3 & 3 & 3.9 & 3.9 \\
\hline History of stroke & No & Yes & No & No & Yes & Yes \\
\hline With ACE inhibitors & & 3.5 & 1.1 & 0.56 & 0.56 & 1.24 \\
\hline $\begin{array}{l}\text { Pneumonia prevention by ACE } \\
\text { inhibitors }\end{array}$ & No & Yes & Yes & No & Yes & No \\
\hline
\end{tabular}


evidence regarding the effects of these drugs on pneumonia. The randomised design of PROGRESS greatly reduced the likelihood of confounding of the analyses and provided an excellent opportunity to explore the validity of the associations reported in observational studies [2,3]. Thus, the key issue is the selection of elderly subjects in terms of ethnicity, poststroke state, performance status, type of ACE inhibitor and swallowing function.

The clinical epidemiology research group of ETMINAN et al. [8] recently reported that no association was found between the use of ACE inhibitors or angiotensin II receptor blockers (ARBs) and risk of hospitalisation secondary to CAP. The study further confirmed the limited efficacy of ACE inhibitors on the risk reduction of hospitalisation due to pneumonia in a white population. As we speculated, ARBs did not have any role in the prevention of aspiration pneumonia.

Stroke and post-stroke patients often exhibit a normal cough reflex, but not swallowing reflex, and the small volume of aspirated materials due to impaired swallowing during night is a key factor for the risk of pneumonia $[9,10]$. Hence, a ten times higher rate of pneumonia in post-stroke patients without significant neurological deficit, compared with the rate of pneumonia in normal elderly [5]. Furthermore, the agedependent impairment of upper airway reflexes should be carefully considered for the mechanism of CAP in the elderly irrespective of the history of stroke.

Finally, we emphasise that aspiration and silent aspiration are very important mechanisms of aspiration pneumonia. Silent aspiration is very common in patients with stroke and frail elderly patients, and nasogastric tube feeding without swallowing rehabilitation or oral care cannot reduce the pneumonia risk in patients with swallowing disorders [11].

We believe that angiotensin-converting enzyme inhibitors could prevent aspiration pneumonia in selected elderly patients. Post-stroke and the frail elderly are the best candidates for the pneumonia risk reduction by angiotensinconverting enzyme inhibitors [12]. However, these merits may not be consistently observed in Caucasian elderly patients with or without stroke.

\section{S. Teramoto, H. Yamamoto, Y. Yamaguchi, Y. Hanaoka, M.} Ishii, S. Hibi and Y. Ouchi

Dept of Geriatric Medicine, Dept of Urology, Graduate School of Medicine, University of Tokyo, Tokyo, Japan.

\section{REFERENCES}

1 van de Garde EM, Souverein PC, van den Bosch JM, Deneer VH, Leufkens HG. Angiotensin-converting enzyme inhibitor use and pneumonia risk in a general population. Eur Respir J 2006; 27: 1217-1222.

2 Sekizawa K, Matsui T, Nakagawa T, Nakayama K, Sasaki H. ACE inhibitors and pneumonia. Lancet 1998; 352: 1069.

3 Arai T, Yasuda Y, Toshima S, Yoshimi N, Kashiki Y. ACE inhibitors and pneumonia in elderly people. Lancet 1998; 352: 1937-1938.
4 Teramoto S, Ouchi Y. ACE inhibitors and prevention of aspiration pneumonia in elderly hypertensives. Lancet 1999; 353: 843.

5 Ohkubo T, Chapman N, Neal B, Woodward M, Omae T, Chalmers J. Effects of an angiotensin-converting enzyme inhibitor-based regimen on pneumonia risk. Am J Respir Crit Care Med 2004; 169: 1041-1045.

6 Woodhead MA, Macfarlane JT, McCracken JS, Rose DH, Finch RG. Prospective study of the aetiology and outcome of pneumonia in the community. Lancet 1987; 1: 671-674.

7 Jokinen C, Heiskanen L, Juvonen $\mathrm{H}$, et al. Incidence of community-acquired pneumonia in the population of four municipalities in eastern Finland. Am J Epidemiol 1993; 137: 977-988.

8 Etminan M, Zhang B, Fitzgerald M, Brophy JM. Do angiotensin-converting enzyme inhibitors or angiotensin II receptor blockers decrease the risk of hospitalization secondary to community-acquired pneumonia? A nested case-control study. Pharmacotherapy 2006; 26: 479-482.

9 Teramoto S, Ishii T, Yamamoto $\mathrm{H}$, et al. Significance of chronic cough as a defence mechanism or a symptom in elderly patients with aspiration and aspiration pneumonia. Eur Respir J 2005; 25: 210-211.

10 Teramoto S, Matsuse T, Fukuchi Y, Ouchi Y. Simple twostep swallowing provocation test for elderly patients with aspiration pneumonia. Lancet 1999; 353: 1243.

11 Teramoto S, Ishii T, Yamamoto H, Yamaguchi Y, Ouchi Y. Nasogastric tube feeding is a cause of aspiration pneumonia in ventilated patients. Eur Respir J 2006; 27: 436-437.

12 Teramoto S, Kume H, Fukuchi Y. Antihypertensive drugs in Japan. Lancet 2001; 357: 720-721.

DOI: $10.1183 / 09031936.00115106$

\section{From the authors:}

I would like to thank S. Teramoto and co-workers for their response to the study my co-workers and I performed on the effects of angiotensin-converting enzyme (ACE) inhibitors on the risk of acquiring pneumonia. Indeed, we could not confirm an association between the use of ACE inhibitors and the risk of pneumonia in a general population. This, however, does not exclude any beneficial effects of ACE inhibitors in specified patient subgroups.

As mentioned in our introduction and by S. Teramoto and coworkers, it is known that patients with a history of stroke do have a higher risk of acquiring pneumonia, which is particularly due to a reduced cough and swallowing reflex $[1,2]$. That ACE inhibitors can be beneficial in these patients is already widely reported [3-5]. We aimed to study whether this protective effect can also be extended to the general population. Unfortunately, we were not able to test modification of the association through stroke, as data on stroke history were sparsely available in the database.

Concerning ethnicity, the reason why the association could not be confirmed in the non-Asian participants of the Perindopril Protection Against Recurrent Stroke Study (PROGRESS) is still subject to speculation. Genetic differences should certainly be considered. However, OHKUBO et al. [4] were unable to show an influence of the ACE I/D polymorphism on the protective 